\title{
High Lactate Dehydrogenase 5 Expression Correlates with High Tumoral and Stromal Vascular Endothelial Growth Factor Expression in Gastric Cancer
}

\author{
Hee Sung Kim ${ }^{a}$ Hee Eun Lee ${ }^{b}$ Han-Kwang Yang ${ }^{c}$ Woo Ho Kim ${ }^{b}$ \\ ${ }^{a}$ Department of Pathology, Chung Ang University, and Departments of b Pathology and ' Surgery, Seoul National University \\ College of Medicine, Seoul, Republic of Korea
}

\section{Key Words}

Disease-free survival · Gastric cancer · Lactate dehydrogenase $5 \cdot$ Overall survival $\cdot$ Vascular endothelial growth factor

\begin{abstract}
Background: Lactate dehydrogenase 5 (LDH5) is a major lactate dehydrogenase isoenzyme catalyzing the transformation of pyruvate to lactate to provide anaerobic energy. Vascular endothelial growth factor (VEGF) is expressed in both tumor and stromal cells in gastric cancer. Our aim was to study the prognostic effect of LDH5, and tumoral and stromal expression of the angiogenic factor VEGF in gastric cancer, and the intercorrelation of tissue expression of both factors. Methods: Tissue microarray analysis of 382 consecutive gastric cancer resection specimens was used for immunohistochemistry of LDH5 and VEGF, and expression of LDH5, tumoral VEGF, and stromal VEGF was categorized into low and high groups. Results: High expression was observed for LDH5 in 57.9\% (219/378), tumoral VEGF in 35.7\% (136/381), and stromal VEGF in 58.5\% (223/381) of the specimens. Regarding high expression of LDH5 and VEGF, significant associations with intestinal type, advanced gastric cancer, lymph node metastasis, higher TNM stage, and upper-third location were noted. Positive intercorrelations occurred among the expression of LDH5 and VEGF. Results of survival analyses revealed a significant association of high expres-
\end{abstract}

sion of LDH5 and VEGF with lower survival (overall and disease-free survival). Five-year survival rates were significantly lower in tumors with high LDH5 and tumoral VEGF expression in diffuse- or mixed-type cancers and high expression of stromal VEGF in intestinal-type cancer. Conclusion: The results of our study showed that high LDH5 and VEGF expression in both tumor and stroma was a prognostic factor for patients with gastric cancers, especially diffuse- or mixedtype cancers. Therefore, LDH5 expression may play a role in the regulation of tumoral and stromal VEGF expression in gastric cancer. Our results suggest the potential use of LDH5 expression as a biomarker for response to VEGF-targeted therapy.

(c) 2014 S. Karger AG, Basel

\section{Introduction}

Gastric cancer is still the fourth most common malignancy in the world and the most common malignancy in Korea [1]. Surgery is the only possible curative treatment, and results of gastrectomy with respect to survival, morbidity, and mortality have improved through the years [2]. Despite these improvements, up to $80 \%$ of patients resected with curative intent develop locoregional recurrences [3]. Various regimens of adjuvant chemotherapy, either with or without radiotherapy, have been administered to prevent disease relapse and to improve the survival rate [4-6].

\section{KARGER}

E-Mail karger@karger.com www.karger.com/pat (c) 2014 S. Karger AG, Base

$1015-2008 / 14 / 0812-0078 \$ 39.50 / 0$
Dr. Woo Ho Kim

Department of Pathology

Seoul National University College of Medicine

28 Yeongeon-dong, Jongno-gu, Seoul 110-799 (Republic of Korea)

E-Mail woohokim@snu.ac.kr 
Hypoxia frequently develops in various solid tumors and provides a microenvironment with resistance to chemoradiotherapy, resulting in a poor prognosis. Glycolysis is a major source for the production of ATP from glucose, which is transformed to pyruvate while NAD+ (nicotinamide adenine dinucleotide) is reduced to $\mathrm{NADH}$. The fate of the pyruvate molecules produced is dependent on the presence of oxygen. Adequate oxygenation allows for conversion of pyruvate to ATP, water and carbon dioxide, while lack of oxygen or biochemical defects relevant to the electron transport system or the citric acid cycle restrict ATP production to glycolysis. Such an oxidation occurs during the reversible transformation of pyruvate to lactate, a reaction catalyzed by lactate dehydrogenase (LDH) 5 [7].

Aerobic glycolysis has been shown to be under the direct control of hypoxia-inducible factors (HIF- $1 \alpha$ and $2 \alpha$ ) in the transcription of a variety of genes involved in angiogenesis, glycolysis, and apoptosis, including vascular endothelial growth factor (VEGF) and LDHA [8].

$\mathrm{LDH}$ is involved in the reversible transformation of pyruvate, the end product of glycolysis, to lactate. The LDH5 isoenzyme, which is composed of $4 \mathrm{M}$ subunits encoded by the LDHA gene, is the most efficient in catalyzing the conversion of pyruvate to lactate. $\mathrm{LDH}$ is formed by the arrangement of up to 4 copies of two different subunits: subunit LDHH is encoded by the LDHB gene and is ubiquitously expressed in healthy tissues, whereas subunit LDHM is encoded by the HIF- 1 target gene LDHA and is therefore induced by hypoxia. Increased expression of LDH5 is one of the hallmarks of cancer cells. Elevated expression of LDH5 is an unfavorable prognosticator in many human tumors, including non-small cell lung cancer, endometrial cancer, and colorectal cancer [7, 9-11].

VEGF is the most commonly expressed cytokine of oxygen-regulated proteins. VEGF-A is the most important proangiogenic factor for the formation and maturation of novel tumor blood vessels. In tumor development, the angiogenic switch is associated with the onset of expression and secretion of angiogenic factors by tumor cells. Secretion of growth factors by tumor cells leads to a complex interplay with subsequent stromal secretion of growth factors and activation of endothelial cell receptors [12]. Angiogenic markers are important in the interaction between different stromal and tumor cells [13]. VEGF also increases capillary leakiness and was first identified as a vascular permeability factor [14].

Most studies addressing the significance of VEGF in angiogenesis have focused on tumor cell expression. As there is growing recognition that the tumor stroma plays a critical role in tumorigenesis [15], a complex interplay between tumor and stromal cells (e.g. macrophages, fibroblasts, lymphocytes, granulocytes and plasma cells) has been described in angiogenesis $[14,16]$.

In this study, we graded VEGF expression in tumor and stroma of gastric cancer separately in order to explore how their expression correlates with LDH5 expression in gastric cancer tissue. We assessed the prognostic significance of LDH5 and VEGF expression in gastric cancer patients treated with curative resection and adjuvant chemotherapy.

\section{Materials and Methods}

\section{Patients and Clinical Samples}

The study cohort included 404 consecutive patients who underwent curative gastrectomy for primary gastric cancer between January 1, 2004, and December 31, 2004, at the Seoul National University Hospital. The cohort consisted of 297 men and 107 women with a mean age of 58.1 years (range: $28-86$ years). Information on tumor location was obtained for 403 cases, the upper third in 73 , middle third in 113 , lower third in 209 , and the entire stomach in 8 cases. The histological type was classified as intestinal in 174, diffuse in 158, and mixed in 72 cases based on the Lauren classification. There were 128 early and 276 advanced gastric cancers. Lymph node metastases were present in 190 cases and absent in 214 cases. One hundred ninety-nine patients were diagnosed as stage I, 87 as stage II, 82 as stage III, and 36 as stage IV (table 1). Adjuvant chemotherapy following surgery was performed in 228 patients: 23 patients in stage I, 87 in stage II, 82 in stage III, and 36 in stage IV. The mean follow-up period was 56.3 months (range: $2-99$ months). Local recurrence was noted in $96(23.8 \%)$, distant metastasis in $8(2.0 \%)$, and gastric cancer-related death in 91 of 404 patients (22.5\%).

This study was approved by the Institutional Review Board of the Seoul National University Hospital (H-1010-065-336). Patient survival data, including dates and causes of death, were obtained from the Korean Central Cancer Registry, Ministry of Health and Welfare, Republic of Korea. Standard histopathological examination included the assessment of cancer type and pathological tumor stage according to the criteria established by the 6th edition of the AJCC Staging Manual [17].

\section{Immunohistochemistry}

For tissue microarray analysis, three core tissue specimens (diameter: $2 \mathrm{~mm}$ ) were obtained from individual paraffin-embedded representative gastric cancer tissue samples (donor blocks) and arranged in three sets of new recipient paraffin blocks (tissue microarray blocks) using a trephine apparatus (Superbiochips Laboratories, Seoul, Republic of Korea). Each tissue microarray block contained up to 60 cores. From the tissue microarray blocks, sections of $4-\mu \mathrm{m}$ thickness were deparaffinized and rehydrated in graded alcohol. Antigen retrieval was achieved by pressure cooking in $0.01 \mathrm{~mol} / \mathrm{l}$ citrate buffer for $5 \mathrm{~min}$. The sheep polyclonal antibody 9002 (Abcam, Cambridge, UK) raised against human LDH5, purified from human placenta [11, 18, 19], and VEGF (1:200, sc-7269; Santa Cruz, Calif., USA) were used for immunohistochemistry. 
Table 1. Clinicopathologic profiles of 404 primary gastric cancer (GC) patients analyzed in this study

\begin{tabular}{|c|c|c|}
\hline & $\mathrm{n}$ & $\%$ \\
\hline \multicolumn{3}{|l|}{ Gender } \\
\hline Total & 404 & 100 \\
\hline Male & 297 & 73.5 \\
\hline Female & 107 & 26.5 \\
\hline \multicolumn{3}{|l|}{ Age } \\
\hline$<60$ years & 201 & 49.8 \\
\hline$\geq 60$ years & 203 & 50.2 \\
\hline \multicolumn{3}{|l|}{ Tumor location } \\
\hline Upper & 73 & 18.1 \\
\hline Middle & 113 & 28 \\
\hline Lower & 209 & 51.7 \\
\hline Entire & 8 & 2 \\
\hline Not recorded & 1 & 0.2 \\
\hline \multicolumn{3}{|l|}{ Lauren classification } \\
\hline Intestinal & 174 & 43.1 \\
\hline Diffuse & 158 & 39.1 \\
\hline Mixed & 72 & 17.8 \\
\hline \multicolumn{3}{|l|}{ Tumor invasion } \\
\hline Early GC & 128 & 31.7 \\
\hline Advanced GC & 276 & 68.3 \\
\hline \multicolumn{3}{|l|}{$\mathrm{N}$ stage } \\
\hline No & 190 & 47 \\
\hline N1 & 214 & 53 \\
\hline \multicolumn{3}{|l|}{ TNM stage } \\
\hline I & 199 & 49.3 \\
\hline II & 87 & 21.5 \\
\hline III & 82 & 20.3 \\
\hline IV & 36 & 8.9 \\
\hline
\end{tabular}

Table 2. LDH5 grading system based on the intensity and extent of cytoplasmic and nuclear staining

\begin{tabular}{llc}
\hline & Score & $\mathrm{n}(\%)$ \\
\hline $\begin{array}{l}\text { Complete absence of LDH5 reactivity } \\
\begin{array}{l}\text { Weak cytoplasmic reactivity } \\
\quad \text { (regardless of the extent) }\end{array}\end{array}$ & low (negative) & $8(2.1)$ \\
$\begin{array}{c}\text { Strong cytoplasmic reactivity in } \\
\quad<50 \% \text { of cells }\end{array}$ & low & $110(29.1)$ \\
$\begin{array}{c}\text { Nuclear expression in sporadic cells } \\
\quad(<10 \%)\end{array}$ & low & $15(4.0)$ \\
$\begin{array}{c}\text { Strong cytoplasmic expression in } \\
\quad>50 \% \text { of cells }\end{array}$ & high & $26(6.9)$ \\
$\begin{array}{l}\text { Nuclear expression in }>10 \% \text { of cells } \\
\text { Total }\end{array}$ & high & $146(38.6)$ \\
\hline
\end{tabular}

The percentage of cancer cells with cytoplasmic and nuclear LDH5 expression was assessed separately and then combined in a grading system proposed by Giatromanolaki et al. [11,20] and Koukourakis et al. [18] (table 2). The gastric adenocarcinomas in the series were divided into tumors with high and low LDH5 expression.

Cytoplasmic positivity for VEGF was separately evaluated in tumor and stromal cells. Immunoreactivity was scored as the per- centage of positive to total tumor cells for tumoral VEGF expression and as the percentage of positive to total stromal cells for stromal VEGF expression. Percentage scores were categorized using a four-category scoring system: $0=$ no reactivity; $1=0-25 \% ; 2=$ $26-50 \% ; 3=51-75 \%$, and $4=76-100 \%$. Scores of 3 and 4 were grouped as high VEGF expression and scores of $0-2$ as low VEGF expression.

\section{Statistical Analyses}

The SPSS 15.0 package was applied for statistical analyses. The $\chi^{2}$ test was used to determine correlations between each protein and clinicopathologic variables, and intercorrelations in protein expression. Survival curves for overall (OS) and disease-free survival (DFS) were plotted using the Kaplan-Meier method, and the log-rank test was employed to determine statistically significant differences between life tables. Five-year survival rates were obtained with the life table method. All $\mathrm{p}$ values are two sided and values of $\mathrm{p}<0.05$ were considered statistically significant.

\section{Results}

Immunohistochemical Expression of LDH5

Normal gastric mucosa showed weak or moderate nuclear staining of epithelial cells in antral and fundic glands. The frequency of each grade of LDH5 expression is shown in table 2. LDH5 expression was increased in $57.9 \%$ (219/378 patients) of the gastric adenocarcinomas studied. Immunohistochemical expression showed a nuclear and/or cytoplasmic pattern in gastric cancer cells (fig. 1a-c).

\section{Immunohistochemical Expression of VEGF}

In normal gastric mucosa, no or weak cytoplasmic expression was observed in both epithelial and stromal cells. VEGF expression was increased in the cytoplasm of tumoral cells in $35.7 \%$ (136/381 patients) and in stromal cells in 58.5\% (223/381 patients). Immunohistochemical expression showed a cytoplasmic pattern in both tumoral and stromal cells (fig. 1a-c).

\section{Association of LDH5 and VEGF Expression with Histopathological Variables}

High LDH5 expression was associated with upper tumor location, intestinal type, advanced gastric cancer, lymph node metastasis, and higher TNM stage; high tumoral VEGF expression showed an association with older age ( $\geq 60$ years), upper tumor location, intestinal type, advanced gastric cancer, lymph node metastasis, and higher TNM stage. Increased stromal VEGF expression was associated with older age ( $\geq 60$ years), intestinal type, advanced gastric cancer, lymph node metastasis, and higher TNM stage (table 3 ).
Kim/Lee/Yang/Kim 

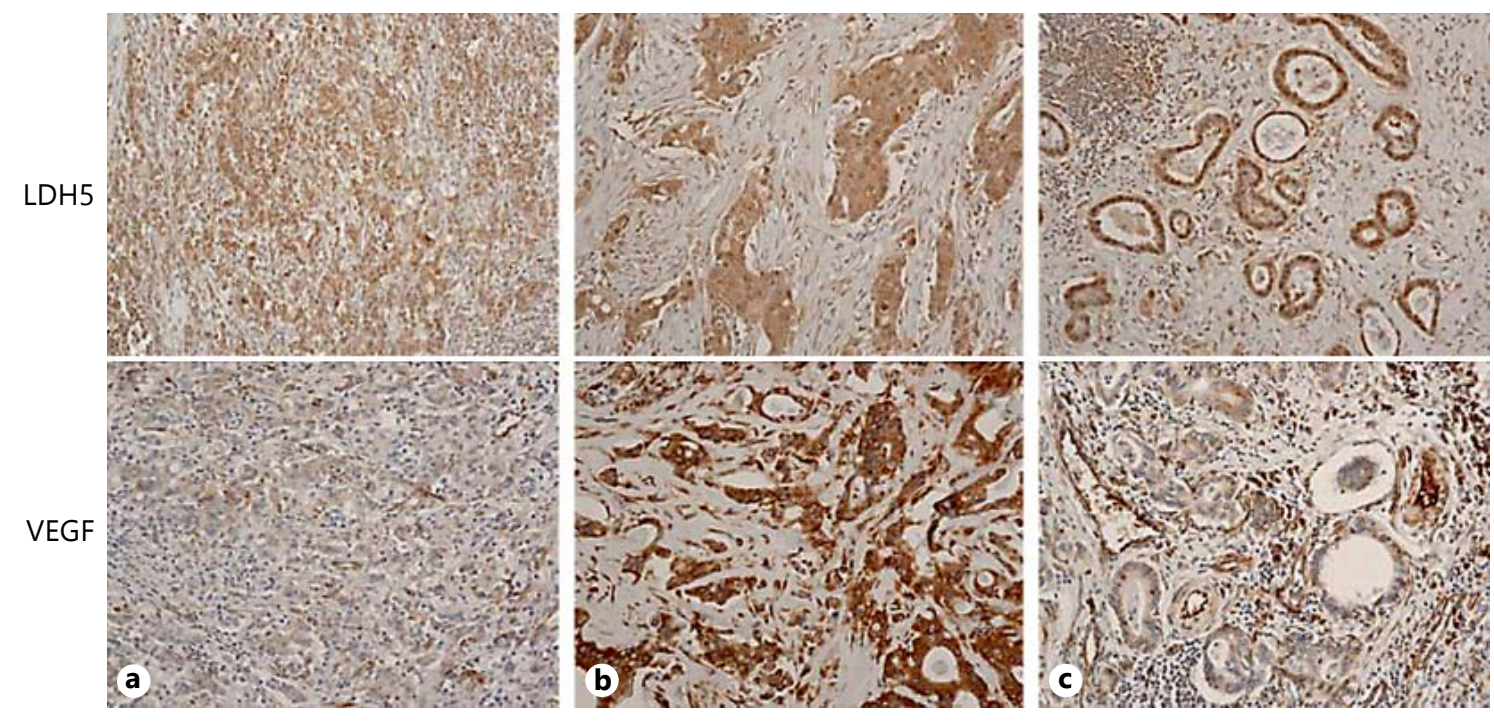

Fig. 1. Immunohistochemical staining of LDH5 and VEGF in tissue sections of human gastric cancer $(\times 200)$. a Low LDH5, low stromal VEGF expression. b High LDH5, high epithelial and stromal VEGF expression. c High LDH5, high stromal VEGF.

Table 3. Clinicopathologic correlation of LDH5 and VEGF expression in gastric cancer (GC)

\begin{tabular}{|c|c|c|c|c|c|c|c|c|c|c|c|c|c|c|c|c|}
\hline & & \multicolumn{5}{|c|}{ LDH5 } & \multicolumn{5}{|c|}{ Tumoral VEGF } & \multicolumn{5}{|c|}{ Stromal VEGF } \\
\hline & & $\mathrm{n}$ & $\%$ & $\mathrm{n}$ & $\%$ & $\mathrm{p}$ & $\mathrm{n}$ & $\%$ & $\mathrm{n}$ & $\%$ & $\mathrm{p}$ & $\mathrm{n}$ & $\%$ & $\mathrm{n}$ & $\%$ & $\mathrm{p}$ \\
\hline \multicolumn{2}{|l|}{ Total patients } & 159 & 42.1 & 219 & 57.9 & & 245 & 64.3 & 136 & 35.7 & & 158 & 41.5 & 223 & 58.5 & \\
\hline \multirow[t]{2}{*}{ Gender } & Male & 113 & 40.8 & 164 & 59.2 & 0.408 & 175 & 62.7 & 104 & 37.3 & 0.287 & 108 & 38.7 & 171 & 61.3 & 0.071 \\
\hline & Female & 46 & 45.5 & 55 & 54.5 & & 70 & 68.6 & 32 & 31.4 & & 50 & 49 & 52 & 51 & \\
\hline Age & $\geq 60$ years & 75 & 39.1 & 117 & 60.9 & & 108 & 56.5 & 83 & 43.5 & & 60 & 31.4 & 131 & 68.6 & \\
\hline \multirow{2}{*}{ Lauren } & Intestinal & 57 & 34.3 & 109 & 65.7 & 0.007 & 90 & 53.9 & 77 & 46.1 & $<0.001$ & 59 & 35.3 & 108 & 64.7 & 0.032 \\
\hline & Diffuse/mixed & 102 & 48.1 & 110 & 51.9 & & 155 & 72.4 & 59 & 27.6 & & 99 & 46.3 & 115 & 53.7 & \\
\hline \multirow[t]{2}{*}{ Invasion } & Advanced GC & 97 & 36.7 & 167 & 63.3 & 0.001 & 154 & 58.1 & 111 & 41.9 & $<0.001$ & 85 & 32.1 & 180 & 67.9 & $<0.001$ \\
\hline & Early GC & 62 & 54.4 & 52 & 45.6 & & 91 & 78.4 & 25 & 21.6 & & 73 & 62.9 & 43 & 37.1 & \\
\hline $\mathrm{N}$ stage & No & 83 & 48.5 & 88 & 51.5 & 0.02 & 126 & 72 & 49 & 28 & 0.004 & 96 & 54.9 & 79 & 45.1 & $<0.001$ \\
\hline TNM stage & IV & 12 & 34.3 & 23 & 65.7 & & 17 & 51.5 & 16 & 48.5 & & 6 & 18.2 & 27 & 81.8 & \\
\hline \multirow{4}{*}{ Location } & Upper & 22 & 31 & 49 & 69 & 0.046 & 40 & 57.1 & 30 & 42.9 & 0.014 & 26 & 37.1 & 44 & 62.9 & 0.082 \\
\hline & Middle & 45 & 45.5 & 54 & 54.5 & & 79 & 74.5 & 27 & 25.5 & & 55 & 51.9 & 51 & 48.1 & \\
\hline & Lower & 91 & 45.7 & 108 & 54.3 & & 123 & 62.4 & 74 & 37.6 & & 75 & 38.1 & 122 & 61.9 & \\
\hline & Entire & 1 & 12.5 & 7 & 87.5 & & 2 & 28.6 & 5 & 71.4 & & 2 & 28.6 & 5 & 71.4 & \\
\hline
\end{tabular}

\section{Correlation of LDH5 Expression with Tumoral and}

Stromal VEGF Expression in Gastric Cancers

A correlation study of protein expression levels was available in 360 cases for LDH5 versus tumoral and stromal VEGF, and in 381 cases for tumoral versus stromal
VEGF, respectively. Significant positive correlations were noted for all the comparative pairs mentioned ( $\mathrm{p}<0.05$; table 4).

Among 381 cases available for tumoral and stromal VEGF expression, 148 (38.8\%) cases showed high expres- 
Table 4. Association of LDH5 and tumoral and stromal VEGF expression in gastric cancer

\begin{tabular}{|c|c|c|c|c|c|c|c|c|c|c|c|}
\hline & & \multicolumn{5}{|c|}{ LDH5 } & \multicolumn{5}{|c|}{ Tumoral VEGF } \\
\hline & & \multicolumn{2}{|l|}{ low } & \multicolumn{3}{|l|}{ high } & \multicolumn{2}{|l|}{ low } & \multicolumn{3}{|c|}{ high } \\
\hline & & $\mathrm{n}$ & $\%$ & $\mathrm{n}$ & $\%$ & $\mathrm{p}$ & $\mathrm{n}$ & $\%$ & $\mathrm{n}$ & $\%$ & $\mathrm{p}$ \\
\hline \multirow[t]{2}{*}{ Tumoral VEGF } & low & 108 & 30 & 119 & 33.1 & 0.001 & & & & & \\
\hline & high & 39 & 10.8 & 94 & 26.1 & & & & & & \\
\hline \multirow[t]{2}{*}{ Stromal VEGF } & low & 74 & 20.6 & 72 & 20 & 0.002 & 148 & 38.8 & 10 & 2.6 & $<0.001$ \\
\hline & high & 73 & 20.3 & 141 & 39.2 & & 97 & 25.5 & 126 & 33.1 & \\
\hline
\end{tabular}

sion in both, $10(2.6 \%)$ showed high expression only in tumor cells, 97 (25.5\%) showed high expression only in stromal cells, and 126 (33.1\%) showed low expression in both.

\section{Survival Analyses by LDH5 and VEGF Expression}

The patients with high LDH5 expression had a significantly shorter DFS compared with those with low LDH5 expression. No significant association was noted between LDH5 expression and OS, while a significant association was found between high tumoral VEGF expression and poor DFS. High stromal VEGF expression showed an association with both poor OS and poor DFS (fig. 2).

The cases were classified into intestinal and diffuse or mixed types and 5-year survival rates were analyzed in two histological subgroups. High LDH5 expression and tumoral VEGF expression were associated with lower 5 -year survival rates in patients with diffuse or mixed type ( $p=0.007$ and $p=0.027$, respectively). In contrast, high stromal VEGF expression was associated with lower 5 -year survival rates in patients with intestinal type $(\mathrm{p}=$ 0.005; table 5).

\section{Discussion}

VEGFs, apparently the most important angiogenic factors, are prime regulators of both physiological and pathological angiogenesis in malignancy [21]. Of particular importance, tissue oxygen tension tightly regulates VEGF levels. Exposure to hypoxia induces rapid and reversible expression of VEGF through both increased mRNA transcription and stabilization. Thus, hypoxic upregulation of VEGF provides a compensatory mechanism by which tissues can increase their oxygenation via the induction of blood vessel growth. Normoxia downregulates VEGF production and leads to the regression of certain newly formed blood vessels.
Both the LDHA and VEGF genes are transcriptionally regulated by HIFs, therefore, serum $\mathrm{LDH}$ is assumed to serve as a predictive marker of response to the VEGF receptor (VEGFR) inhibitor combination with chemotherapy [22]. In our study, high LDH5 expression in gastric cancer tissue was correlated with both tumoral and stromal VEGF expression. The Lauren classification for gastric cancer has been used for a long time as consistent categories based on differentiation [23]. The results of our study revealed that expression of LDH5 and VEGF was more frequently increased in the intestinal type, and high expression of LDH5 and tumoral VEGF showed a significant correlation with poor prognosis in diffuse- or mixed-type gastric cancer, while stromal VEGF expression was correlated with outcome, regardless of the histologic type. The reason for this phenomenon is not clear; tumoral cell differentiation might be linked to lactate production and the regulation of angiogenesis.

In a meta-analysis of tissue VEGF expression as a prognosticator in gastric cancer, there are 26 eligible studies: 20 positive and 6 negative results. VEGF binds to VEGFR-1 (Flt-1) and VEGFR-2 (KDR/Flk-1), which is mainly expressed in vascular endothelial cells. VEGF-A, usually simply referred to as VEGF, is believed to play a major role in tumor growth and metastasis [24].

In the 1920s, Otto Warburg reported that in tumor cells of ascites rates of glucose consumption and lactate production were increased despite the availability of sufficient oxygen for the complete oxidation of glucose. The Warburg effect is regarded as a metabolic hallmark of aggressive tumors; however, the phenotype has also been observed in nontransformed cells during rapid proliferation [25]. It is widely believed that most tumor cells derive the major portion of metabolic energy from glycolysis rather than mitochondrial oxidation [26]. Reduction of pyruvate to lactate also allows glycolytic cells to maintain pyruvate levels low enough to avoid cell death $[26,27]$. 
Fig. 2. Kaplan-Meier analysis of OS and DFS of gastric cancer patients according to LDH5 (a, b), tumoral VEGF (c, d), and stromal VEGF expression (e, f). Dotted line = Low expression; solid line $=$ high expression.

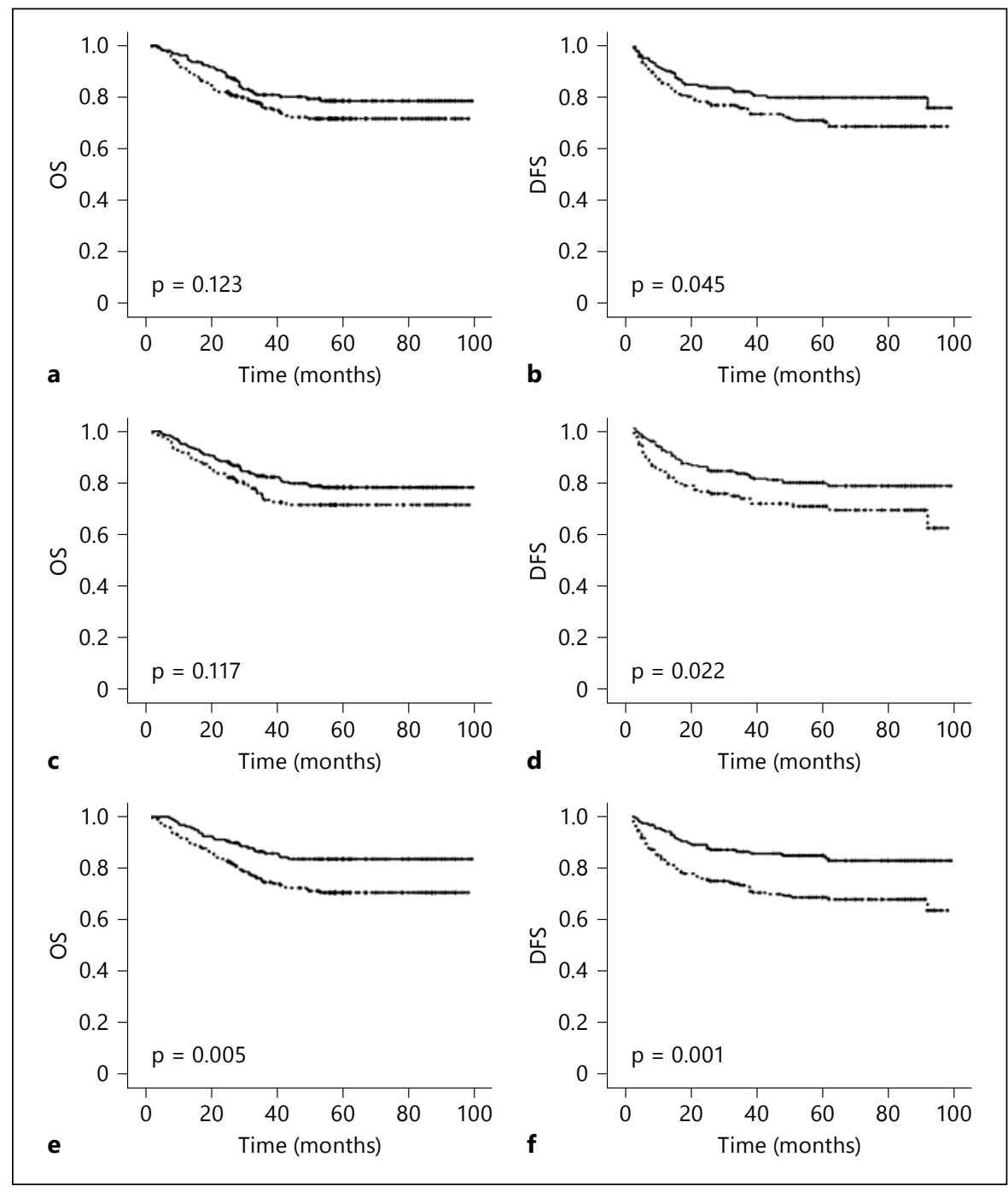

This reversible reaction is catalyzed by $\mathrm{LDH}$. Lactate produced by tumor cells may also affect tumor progression and metastasis [28].

There are 5 component isoenzymes as a result of the 5 different combinations produced by 2 polypeptide chains encoded by separate genes ( $\mathrm{M}$ and $\mathrm{H})$. $\mathrm{LDH} 1$ is composed of $4 \mathrm{H}$ subunits, and LDH5 of $4 \mathrm{M}$ subunits. As the number of $\mathrm{M}$ over $\mathrm{H}$ chains increases, the $\mathrm{LDH}$ isoenzyme becomes more efficient in catalyzing the conversion of pyruvate to lactate (LDH5), while an increase of $\mathrm{H}$ over $\mathrm{M}$ chains (LDH1) favors the conversion of pyruvate to acetyl-CoA that enters into the citric acid (Krebs) cycle. The prevailing type of LDH is dependent upon the metabolic demands of a particular tissue [29].

VEGF is a major inducer of angiogenesis and vessel permeability [30]. Expression of VEGF in tumor cells is
Table 5. Five-year survival rates according to LDH5, and tumoral and stromal VEGF expression in histological subgroups

\begin{tabular}{llll}
\hline Histological type/category & Expression & 5-year survival, \% & $\mathrm{p}$ \\
\hline Intestinal type & & & \\
LDH5 & low & 75.6 & 0.585 \\
Tumoral VEGF & high & 80.4 & \\
& low & 79.5 & 0.619 \\
Stromal VEGF & high & 78.2 & \\
& low & 91.1 & 0.005 \\
\hline Diffuse or mixed type & high & 72.0 & \\
LDH5 & low & 80.2 & 0.007 \\
& high & 63.6 & 0.027 \\
Tumoral VEGF & low & 79.0 & \\
Stromal VEGF & high & 63.9 & 0.085 \\
& low & 79.0 & \\
\hline
\end{tabular}


thought to be largely attributable to the hyperpermeability of tumor vessels, and increased permeability results in leakage of several plasma proteins, including fibrinogen and other clotting proteins. This can lead to the deposition of fibrin in the extravascular space, which subsequently retards the clearance of edema fluid and transforms the normally anti-angiogenic stroma of normal tissue into a proangiogenic environment. VEGF ligands expressed by tumor cells or host stromal cells stimulate VEGFR-1, VEGFR-2, or VEGFR-3 expressed by endothelial, lymphendothelial, or hematopoietic cells. Stimulation of VEGFR-1- and VEGFR-2-positive endothelial cells by VEGF activates proliferation, migration, survival, and vascular permeability [31].

There are limitations of both heterogeneity of tissue microarray-based immunohistochemistry and heterogeneity of gastric cancer itself in our results [32, 33]. However, the results of our study of stromal VEGF showed a strong correlation between tumoral and stromal VEGF expression in gastric cancer tissue and the prognostic effect showed a similar pattern according to the expression level. In contrast, in non-small cell lung cancers, an inverse prognostic impact of angiogenic marker expression in tumor cells versus stromal cells was reported [34]. A significant association of LDH5 and VEGF expression was reported in endometrial cancer [11], and a direct correlation of LDH5 with VEGF was noted in non-small cell lung cancer [29]. In colon cancer, no association of LDH5 with either VEGF expression or vascular density was observed $[9,18]$, but the association with phosphorylated kinase domain receptor was significant [9].

Results of our retrospective study showed that high expression of LDH5, and expression of both tumoral and stromal VEGF in gastric cancer are indicators of tumor aggressiveness and a poor outcome, particularly in diffuse- or mixed-type cancers.

\section{Acknowledgments}

The generation of LDH5 expression data was supported by AstraZeneca.

\section{References}

1 IARC: Globocan 2008 Cancer Fact Sheet. http://globocan.iarc.fr/factsheets/cancers/ stomach.asp.

$>2$ Akoh JA, Macintyre IM: Improving survival in gastric cancer: review of 5-year survival rates in English language publications from 1970. Br J Surg 1992;79:293-299.

$>3$ Gunderson LL: Gastric cancer - patterns of relapse after surgical resection. Semin Radiat Oncol 2002;12:150-161.

-4 Hejna M, Wohrer S, Schmidinger M, Raderer M: Postoperative chemotherapy for gastric cancer. Oncologist 2006;11:136-145.

5 Macdonald JS, Smalley SR, Benedetti J, Hundahl SA, Estes NC, Stemmermann GN, Haller DG, Ajani JA, Gunderson LL, Jessup JM, Martenson JA: Chemoradiotherapy after surgery compared with surgery alone for adenocarcinoma of the stomach or gastroesophageal junction. N Engl J Med 2001;345:725-730.

$\checkmark 6$ Di Costanzo F, Gasperoni S, Manzione L, Bisagni G, Labianca R, Bravi S, Cortesi E, Carlini P, Bracci R, Tomao S, Messerini L, Arcangeli A, Torri V, Bilancia D, Floriani I, Tonato $M$, Dinota A, Strafiuso G, Corgna E, Porrozzi S, Boni C, Rondini E, Giunta A, Monzio Compagnoni $\mathrm{B}$, Biagioni F, Cesari M, Fornarini G, Nelli F, Carboni M, Cognetti F, Enzo MR, Piga A, Romiti A, Olivetti A, Masoni L, De Stefanis M, Dalla Mola A, Camera S, Recchia F, De Filippis S, Scipioni L, Zironi S, Luppi G, Italia M, Banducci S, Pisani Leretti A, Massidda B, Ionta MT, Nicolosi A, Canaletti R, Biscottini
B, Grigniani F, Rovei R, Croce E, Carroccio R, Gilli G, Cavalli C, Olgiati A, Pandolfi U, Rossetti R, Natalini G, Foa P, Oldani S, Bruno L, Cascinu S, Catalano G, Catalano V, Lungarotti F, Farris A, Sarobba MG, Trignano M, Muscogiuri A, Francavilla F, Figoli F, Leoni M, Papiani G, Orselli G, Antimi M, Bellini V, Cabassi A, Contu A, Pazzola A, Frignano M, Lastraioli E, Saggese M, Bianchini D, Antonuzzo L, Mela M, Camisa R: Adjuvant chemotherapy in completely resected gastric cancer: a randomized phase III trial conducted by GOIRC. J Natl Cancer Inst 2008;100:388-398.

7 Koukourakis MI, Giatromanolaki A, Sivridis E, Bougioukas G, Didilis V, Gatter KC, Harris AL: Lactate dehydrogenase-5 (LDH-5) overexpression in non-small-cell lung cancer tissues is linked to tumour hypoxia, angiogenic factor production and poor prognosis. $\mathrm{Br}$ J Cancer 2003;89:877-885.

$>8$ Semenza G: Signal transduction to hypoxiainducible factor 1. Biochem Pharmacol 2002; 64:993-998.

-9 Koukourakis MI, Giatromanolaki A, Sivridis E, Gatter KC, Harris AL: Lactate dehydrogenase 5 expression in operable colorectal cancer: strong association with survival and activated vascular endothelial growth factor pathway - a report of the Tumour Angiogenesis Research Group. J Clin Oncol 2006;24: 4301-4308.

10 Koukourakis MI, Giatromanolaki A, Sivridis E, Gatter KC, Trarbach T, Folprecht G, Shi
MM, Lebwohl D, Jalava T, Laurent D, Meinhardt G, Harris AL: Prognostic and predictive role of lactate dehydrogenase 5 expression in colorectal cancer patients treated with PTK787/ZK 222584 (vatalanib) antiangiogenic therapy. Clin Cancer Res 2011;17:48924900.

11 Giatromanolaki A, Sivridis E, Gatter KC, Turley H, Harris AL, Koukourakis MI: Lactate dehydrogenase 5 (LDH-5) expression in endometrial cancer relates to the activated VEGF/ VEGFR2(KDR) pathway and prognosis. Gynecol Oncol 2006;103:912-918.

12 Bremnes RM, Camps C, Sirera R: Angiogenesis in non-small cell lung cancer: the prognostic impact of neoangiogenesis and the cytokines VEGF and bFGF in tumours and blood. Lung Cancer 2006;51:143-158.

13 Ferrara N, Kerbel RS: Angiogenesis as a therapeutic target. Nature 2005;438:967-974.

14 Ferrara N, Gerber HP, LeCouter J: The biology of VEGF and its receptors. Nat Med 2003; 9:669-676.

15 Liotta LA, Kohn EC: The microenvironment of the tumour-host interface. Nature 2001; 411:375-379.

16 Schoppmann SF, Birner P, Stöckl J, Kalt R, Ullrich R, Caucig C, Kriehuber E, Nagy K, Alitalo K, Kerjaschki D: Tumor-associated macrophages express lymphatic endothelial growth factors and are related to peritumoral lymphangiogenesis. Am J Pathol 2002;161: 947-956. 
17 Greene FL, Page DL, Fleming ID: AJCC Cancer Staging Manual. New York, Springer, 2002.

18 Koukourakis MI, Giatromanolaki A, Simopoulos C, Polychronidis A, Sivridis E: Lactate dehydrogenase 5 (LDH5) relates to up-regulated hypoxia inducible factor pathway and metastasis in colorectal cancer. Clin Exp Metastasis 2005;22:25-30.

-19 Zaman K, Ryu H, Hall D, O’Donovan K, Lin KI, Miller MP, Marquis JC, Baraban JM, Semenza GL, Ratan RR: Protection from oxidative stress-induced apoptosis in cortical neuronal cultures by iron chelators is associated with enhanced DNA binding of hypoxia-inducible factor-1 and ATF-1/CREB and increased expression of glycolytic enzymes, p21(waf1/cip1), and erythropoietin. J Neurosci 1999;19:9821-9830.

20 Giatromanolaki A, Sivridis E, Kouskoukis C, Gatter KC, Harris AL, Koukourakis MI: Hypoxia-inducible factors 1alpha and 2alpha are related to vascular endothelial growth factor expression and a poorer prognosis in nodular malignant melanomas of the skin. Melanoma Res 2003;13:493-501.

21 Veikkola T, Alitalo K: VEGFs, receptors and angiogenesis. Semin Cancer Biol 1999;9:211220.

22 Semenza GL, Jiang BH, Leung SW, Passantino R, Concordet JP, Maire P, Giallongo A: Hypoxia response elements in the aldolase A, enolase 1, and lactate dehydrogenase A gene promoters contain essential binding sites for hypoxia-inducible factor 1. J Biol Chem 1996; 271:32529-32537.
23 Lauren P: The two histological main types of gastric carcinoma: diffuse and so-called intestinal-type carcinoma. An attempt at a histoclinical classification. Acta Pathol Microbiol Scand 1965;64:31-49.

24 Liu L, Ma XL, Xiao ZL, Li M, Cheng SH, Wei YQ: Prognostic value of vascular endothelial growth factor expression in resected gastric cancer. Asian Pac J Cancer Prev 2012;13: 3089-3097.

25 Wang T, Marquardt C, Foker J: Aerobic glycolysis during lymphocyte proliferation. Nature 1976;261:702-705.

26 Thangaraju M, Carswell Kristina N, Prasad Puttur D, Ganapathy V: Colon cancer cells maintain low levels of pyruvate to avoid cell death caused by inhibition of HDAC1/ HDAC3. Biochem J 2009;417:379.

27 Thangaraju M, Gopal E, Martin PM, Ananth S, Smith SB, Prasad PD, Sterneck E, Ganapathy V: SLC5A8 triggers tumor cell apoptosis through pyruvate-dependent inhibition of histone deacetylases. Cancer Res 2006;66: 11560-11564.

28 Walenta S, Mueller-Klieser WF: Lactate: mirror and motor of tumor malignancy. Sem Radiat Oncol 2004;14:267-274.
29 Koukourakis MI, Giatromanolaki A, Sivridis E: Lactate dehydrogenase isoenzymes 1 and 5: differential expression by neoplastic and stromal cells in non-small cell lung cancer and other epithelial malignant tumors. Tumour Biol 2003;24:199-202.

30 Berse B, Brown LF, Van de Water L, Dvorak HF, Senger DR: Vascular permeability factor (vascular endothelial growth factor) gene is expressed differentially in normal tissues, macrophages, and tumors. Mol Biol Cell 1992;3:211-220.

31 Hicklin DJ: Role of the vascular endothelial growth factor pathway in tumor growth and angiogenesis. J Clin Oncol 2004;23:10111027.

32 Kim MA, Lee H-J, Yang H-K, Bang Y-J, Kim WH: Heterogeneous amplification of ERBB2 in primary lesions is responsible for the discordant ERBB2 status of primary and metastatic lesions in gastric carcinoma. Histopathology 2011;59:822-831.

33 Kim HS, Kim MA, Hodgson D, Harbron C, Wellings R, O'Connor MJ, Womack C, Yin X, Bang YJ, Im SA, Lee BL, Kim WH: Concordance of ATM (ataxia telangiectasia mutated) immunohistochemistry between biopsy or metastatic tumor samples and primary tumors in gastric cancer patients. Pathobiology 2013;80:127-137.

- 34 Donnem T, Al-Saad S, Al-Shibli K, Delghandi MP, Persson M, Nilsen MN, Busund LT, Bremnes RM: Inverse prognostic impact of angiogenic marker expression in tumor cells versus stromal cells in non small cell lung cancer. Clin Cancer Res 2007;13:6649-6657. 